\title{
The Intelligent Design and Realization of Fire Control System of Practical Training Center in Vocational College
}

\author{
Haijun Yang ${ }^{1, a}$, Xiandong Zhao ${ }^{2, b}$ and Baocheng $\mathrm{Lu}^{3, \mathrm{c},{ }^{*}}$ \\ 'Binzhou Polytechnic No.919, Huanghe 12 Road, Binzhou, Shandong Province, China

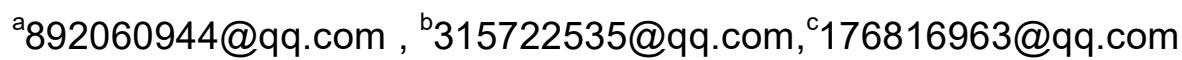

\begin{abstract}
Fire fighting is one of the key monitoring targets of campus security. To improve the maintenance and management of campus fire control facilities and fire evacuation and fire fighting action efficiency, with a training center as an example, the existing automatic fire detection alarm, fire linkage control system on the basis of the application of Internet of things technology, designed to install ZigBee wireless fire detector system, improve the reliability of fire detection and data transmission. Design of an intelligent control system of evacuation and fire control facilities maintenance system, realize the exchange with the fire control center, combined with the campus safety monitoring platform, achieve comprehensive campus security controls.
\end{abstract}

Keywords: Practical training center, fire control intelligent Internet of things design implementation

\section{Introduction}

Colleges and universities have been the key units of fire control monitoring. Because of its personnel density, small building space, complex structure, more combustibles and other characteristics, once a fire occurs, it is very easy to cause a serious production safety accident. As an important teaching place of vocational colleges, the training center undertakes the teaching task of students in the whole college and is the "top priority" of fire prevention.

\section{Research background and current situation}

With the major adjustment of the national talent training strategy, the vocational colleges that use the skills applied talents have entered the vigorous development period. In order to optimize the teaching resources of the college, reduce the repeated investment of the training equipment and improve the utilization ratio of the professional training room, the colleges gradually established the integrated training center. The establishment of the training center solves a series of problems, but also brings about bigger fire hazards. Compared with ordinary teaching and office space, the fire protection of the training center has the following characteristics:

(1) There has a large number of equipment and many sources of fire. As the training center, the teaching equipment is various and complex, especially the parts of the equipment in the operation itself can easily trigger the fire. For example, the welding high temperature and the large amount of spark generated by the metal cutting machine during the welding training.

(2) The actual training center consumes more materials and the fire hazard is large. In order to facilitate the development of practical training courses, training centers tend to store a large number of flammable and explosive materials. Such as nursing professional disinfection use of alcohol, chemical specialty chemicals and so on. Once a fire breaks out, it can be very difficult to save the work.

(3) The power consumption is large, and the electric fire danger is large. The operation of the training equipment consumes a lot of power, which can easily cause an electrical fire accident due to the failure of overload, short circuit and the aging of the line.

Currently, the fire control system mainly relies on fire alarm and integrated control of fire control. By the fire alarm module of fire detectors and manual alarm button for the fire, and then made by integrated fire module fire audible and visual alarm at the same time, complete industry in radio, shutter 
down and closed doors, Windows, etc. Although the system can eliminate the initial fire and delay the spread of fire to some extent, it still shows some shortcomings. Such as the response of fire detection system, the evacuation difficulty of people in the fire, the water and water damage of the high pressure water spray system and the water damage of the valuable experimental instruments.

\section{Overall design of intelligent fire protection system}

Combining with the characteristics of training center for fire prevention and the deficiency of traditional means of fire at a training center in higher vocational colleges as an example, on the basis of the existing fire control facilities, combined with the latest Internet technology and intelligent evacuation system, optimize the design training center of the fire control system.

To achieve the following technical objectives:

(1)The Internet of things technology is applied to realize the all-covering fire detection and visual monitoring of the training center;

(2)We will carry out electronic label registration of all fire equipment in the training center to realize automatic reminder function of maintenance and maintenance.

(3)The design and installation of intelligent control system of evacuation, when the fire broke out, according to fire the elements such as size, direction, intensity, and provide the best personnel evacuation escape route guidance;

(4)The platform realizes the networking of the remote dispatching center of the fire department, and can obtain the most professional guidance in the first time of fire;

(5)The system realizes the networking of the campus monitoring platform, facilitating the transfer of available resources from the college level, the joint prevention of the whole hospital, and preventing the occurrence of other campus emergencies.

1) Framework of intelligent fire fighting system

The main architecture of the intelligent fire control system of the training center is shown in the following figure(1):

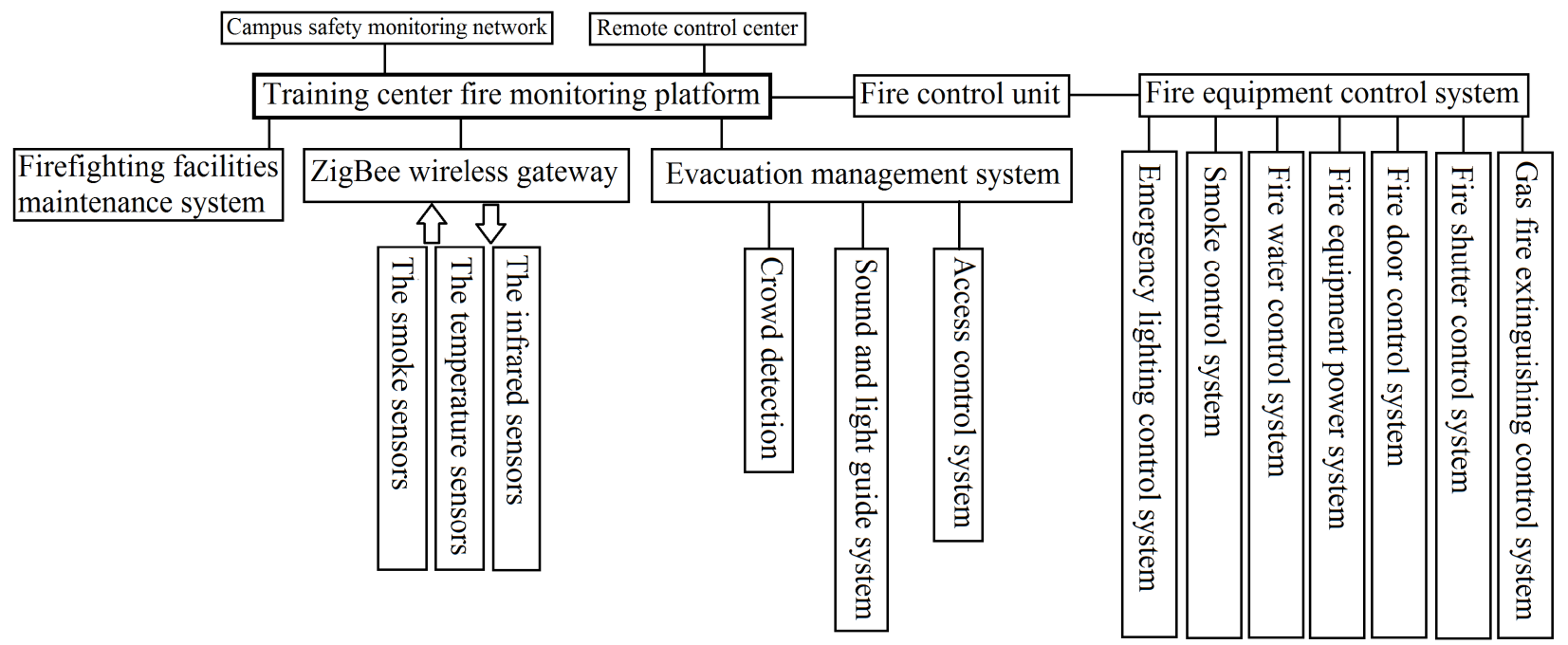

Figure 1 The intelligent fire control system structure of the training center

This system with automatic fire detection alarm system and fire linkage control system as the core, with the system bus to each subsystem of the network, make the system can run independently, and can realize the centralized monitoring and management requirements.

In the early combustion ignition source automatic fire detection alarm system of all kinds of smoke from the burning of fire detector will quickly, light, heat and other physical quantities are collected, after logic to the fire signal wireless transmission in a timely manner to fire monitoring platform. Platform receives the fire signal immediately after the show the location and time of the fire, fire elements such as nature, and according to the preset program issued a joint command and control 
fixed water fire extinguishing system, large gas fire extinguishing system, start the smoke, fire doors, fire shutter fire isolation devices, such as a fire broadcast at the same time, intelligent evacuation crowd. In the fire broke out in the first place will alert sent to the campus safety monitoring platform, facilitate attendant reported, mobilize fire resources, set up campus emergency channel, strengthen campus controls, prevent the occurrence of other events. Can also according to need, the use of this platform to realize connection to a one-click fire monitoring platform, at the same time of a fire alarm, all kinds of information transmitted to the fire department, is advantageous for the firefighters judgment based on the fire effect, professional fire extinguishing measures are put forward, improve the effect of fire.

2) Main module technology implementation plan of the system

The intelligent fire protection platform is optimized and upgraded based on the original fire alarm - fire linkage integration system. In this paper, the fire detection system is improved greatly, and the fire protection equipment maintenance, fault diagnosis system and intelligent evacuation control system are added.

(1)The fire detection system design

This system mainly adopts the Internet of things technology, which can not only avoid the problem of wiring, but also improve the reliability of fire detection system. The basic method is to install ZigBee fire wireless sensor on fire monitoring points first. The ZigBee wireless gateway is then installed to perform daily management of the sensors and can quickly collect the fire signals when a fire occurs. In order to facilitate the installation and improvement of the reliability of the system during the fire, the output module of ZigBee gateway adopts the WiFi mode to realize the docking of the fire management platform through the campus wireless network.

(2)The fire control facilities maintenance system design and implementation plan

Using active and passive RFID tags to the fire control facilities, such as various types of portable or cart type fire extinguishers, fire hose, fire prevention, etc.) to register the electronic, to fire warden will be the technical data of each equipment, maintenance interval input system platform, etc. The program is set to alert the system for the first 15 days before the expiration of the device, and the manual response can remove the alarm. Such as maintenance person before it is due to the equipment maintenance, maintenance after the need to recode equipment and device information need to fire the competent leadership manual confirmation, to reset the maintenance information. The late alarm function cannot be cancelled, and the system will automatically record the information such as the responsibility of maintenance equipment. Only after the completion of the maintenance, re-coding and the supervisor's confirmation procedures, the alarm can be automatically removed.

(3)The implementation plan of intelligent evacuation control and control system technology

Building at the beginning of the fire, fire personnel often due to excessive panic, crowded unexpected accidents, and intelligent control system is the main function of evacuated after the fire, automatically according to the position of the fire, the fire spread, channel, smoke concentration, open the entrance guard system, fire complementation of shutter status and factors such as traffic density through logic operation, intelligent for staff training center in different location of the best escape route.

\section{System test}

(1)The fire auto-detection system performance test

In the training center of each layer, we according to the distribution of the sensor and the sensor type, random $20 \%$ of different types of fire detection sensors, heat, smoke and photographic experiments respectively. For the sensor of the heat sensor, the paper is lit and placed at the bottom of the sensor at a distance of 1 meter. The test shows normal. For the smoke sensor, the cigarette was lit and placed at the bottom of the sensor at the distance of 0.5 meters. The test showed normal. For light-sensitive sensors, the paper was lit and placed 3 meters away from the sensor, and the test showed normal.

(2)The performance test of fire-fighting facilities maintenance system 
We randomly selected four sets of fire extinguishing equipment, set the expiration time of the maintenance of $\mathrm{A}$ and $\mathrm{B}$ equipment to 15 days and 1 hour, and the set expiration time of $\mathrm{C}$ and $\mathrm{D}$ equipment is 1 hour. An hour later, $\mathrm{A}$ and $\mathrm{B}$ issued the expiration reminder, manually removing the reminder; At the same time, the $\mathrm{C}$ and $\mathrm{D}$ equipment issued a dereliction of duty alarm, the reply was invalid, and the alarm was canceled after the re-coding and the supervisor's confirmation.

(3)The intelligent evacuation and control system performance test

We organized three hundred students to conduct fire drill, simulating a fire accident in a training room on the second floor, and the fire shutter brake that spread quickly and multiple channels was put down. After the actual test, the system successfully rationalized every layer of personnel, successfully avoided the fireworks danger zone and crowded corridor, and managed to evacuate the personnel from three different exits.

\section{Conclusion}

After the system has been put into operation, the work pressure of the fire fighting manager has been greatly improved, the work efficiency has been improved, and the campus fire protection has been praised unanimously. Campus fire safety is a string that can never be relaxed. This system is to use the Internet of things technology for support, explore a wisdom training center fire platform construction scheme, for the campus safety and safe community fire monitoring platform for the construction of the accumulation of experience. The next step, can be in this platform, on the basis of using big data cloud computing method, in all aspects of training center, on the basis of monitoring data, the training center for fire risk assessment of the normalized prediction, and can provide you with the best when the fire extinguishing schemes.

\section{References}

[1] LU Juanjuan, Bai Yanmin, Chen Hong. Design and implementation of intelligent fire control system[J].Electronic Measurement Technology,2016,(39)5:97-126.

[2] WANG Zhi-yong, LI Guang, GAO Bo. Design of Intelligent Fire control system based on Internet of things[J].Journal of Hebei Engineering and Technical College Quarterly,2017, (3) :9-12. 